\title{
Anesthetic effects of a three-drugs mixture - comparison of administrative routes and antagonistic effects of atipamezole in mice-
}

\author{
Yumiko KIRIHARA ${ }^{1)}$, Mayumi TAKECHI ${ }^{1)}$, Kaoru KUROSAKI ${ }^{1)}$, Yuta KOBAYASHI ${ }^{2}$, \\ Yoji SAITO ${ }^{3)}$, and Takashi TAKEUCHI ${ }^{4)}$ \\ 1) Department of Experimental Animals, Interdisciplinary Center for Science Research, Organization for Research, \\ Shimane University, 89-1 Enya-cho, Izumo, Shimane 693-8501, Japan \\ 2) Department of Fundamental Nursing, Faculty of Medicine, Shimane University, 89-1 Enya-cho, Izumo, Shimane \\ 693-8501, Japan \\ 3) Department of Anesthesiology, Faculty of Medicine, Shimane University, 89-1 Enya-cho, Izumo, Shimane 693- \\ 8501, Japan \\ 4) Course of Veterinary Laboratory Medicine, Faculty of Agriculture, Tottori University, 4-101 Minami, Koyama-cho, \\ Tottori 680-8533, Japan
}

\begin{abstract}
The anesthetic mixture of medetomidine (MED), midazolam (MID) and butorphanol (BUT) produced anesthetic duration of around 40 minutes ( $\mathrm{min}$ ) in ICR mice. We reported that this anesthetic mixture produced almost the same anesthetic effects in both male and female BALB/c and C57BL/6J strains. Intraperitoneal (IP) administration of drugs has been widely used in mice. However, various injectable routes of the anesthetic mixture may cause different anesthetic effects. First, we examined effects of the anesthetic mixture by subcutaneous (SC) and intravenous (IV) injection compared to IP injection. After injection of the anesthetic mixture, administration of atipamezole (ATI) induced mice recovery from anesthesia. Secondly, we examined how different dosage and optimum injection timing of ATI affected mice recovery from anesthesia. We used an anesthetic score to measure anesthetic duration and a pulse oximeter to monitor vital signs under anesthesia. Usually, drugs from SC injection work more weakly than IP or IV injection. However, we found no significant differences of anesthetic duration among the three different injection routes. Antagonistic effects of ATI $(0.3 \mathrm{mg} / \mathrm{kg}$ and 1.5 $\mathrm{mg} / \mathrm{kg}$ ) worked equally when administered at $30 \mathrm{~min}$ after injection of the anesthetic mixture. Antagonistic effects of ATI $(1.5 \mathrm{mg} / \mathrm{kg})$ were stronger than ATI $(0.3 \mathrm{mg} / \mathrm{kg})$ at $10 \mathrm{~min}$ after injection of the anesthetic mixture. The anesthetic mixture is a useful drug to induce nearly the same anesthetic effects by different injection routes and has an antagonist of ATI which helps mice quickly recover from anesthesia. These results may contribute to the welfare of laboratory animals.
\end{abstract}

Key words: anesthetic mixture, antagonist, atipamezole, mice, pulse oximeter

\section{Introduction}

Due to an abuse problem, ketamine (KET) has been specified as a narcotic in Japan since 2007. Then, we have been searching for an anesthetic that excludes KET.
An anesthetic mixture of medetomidine (MED) $(0.3 \mathrm{mg} /$ $\mathrm{kg}$ b.w.), midazolam (MID) (4 mg/kg b.w.) and butorphanol (BUT) $(5 \mathrm{mg} / \mathrm{kg}$ b.w.) has been introduced recently [13]. This anesthetic mixture was reported to produce anesthetic duration of around $40 \mathrm{~min}$ in ICR

(Received 11 May 2014 / Accepted 7 August 2014 / Published online in J-STAGE 12 September 2014)

Address corresponding: Y. Kirihara, Department of Experimental Animals, Interdisciplinary Center for Science Research, Organization for Re-

search, Shimane University, 89-1 Enya-cho, Izumo, Shimane 693-8501, Japan

(C)2015 Japanese Association for Laboratory Animal Science 
mice. We reported that this anesthetic mixture produced almost the same anesthetic effects of ICR mice in both male and female BALB/c and C57BL/6J strains [14].

Intrapetitoneal (IP) injection of drugs has been widely used in laboratory animals including mice [10], because subcutaneous (SC) injection induces drug effects more slowly and weakly than IP injection [9]. Intravenous (IV) injection produces drug effects more quickly and predictably [8]. However, rapid IV injection of anesthetic drugs is sometimes lethal. Another injectable route of the mixture of three drugs may induce different anesthetic effects, because three drugs have different pharmacological mechanism $[4,5]$ and there may be additive or synergistic effects from each drug.

In this study, we used an anesthetic score to assess the effects of the anesthetic mixture administered by SC and IV injection compared to IP administration. During the experiment, we measured vital signs just before and after injection of the anesthetic drugs, because the parameters such as Oxygen $\left(\mathrm{O}_{2}\right)$-saturation, heart rate and respiratory rate are related to the anesthetic condition of mice under anesthesia [6].

Adminstration of atipamezole (ATI) is a strong antagonist of MED [7]. After injection of the anesthetic mixture, administration of ATI causes mice a rapid recovery from anesthesia. However, neither an appropriate dosage nor an optimum injection timing of ATI after administration of the anesthetic mixture are clear. Then, we examined how the timing of injection and a dosage of ATI affected recovery from anesthesia in mice after administration of the anesthetic mixture.

\section{Materials and Methods}

\section{Animals and housing conditions}

Animal care and experimental procedures were approved by the Animal Research Committee of Shimane University and conducted according to the Regulations for Animal Experimentation at Shimane University.

We used 24 male ICR mice in the experiment. The mice were purchased at 5 weeks of age from a commercial supplier (CLEA Japan, Inc., Tokyo, Japan) and habituated for 2 weeks in the animal room before starting the experiment. The mice were 7 to 9 weeks of age during the experiment.

Four mice were housed in one TPX cage $\left(\mathrm{KN}-600^{\circledR}\right.$, W $220 \times$ L $320 \times$ H 135 mm, Natsume Seisakusho, Co., Ltd., Tokyo, Japan) under a strict light cycle (light on at
7:00 and off at 19:00). Autoclaved bedding (Pure Chip ${ }^{\circledR}$, Shimizu Laboratory Supplies, Co., Ltd., Kyoto, Japan) was provided for each cage and changed once a week.

The animal room was maintained at a constant temperature $\left(23 \pm 2^{\circ} \mathrm{C}\right)$ and humidity $(55 \pm 10 \%)$. The mice were given a standard diet $\left(\mathrm{MF}^{\circledR}\right.$, Oriental Yeast Co., Ltd., Tokyo, Japan) and filtered tap water by an automatic water supply system ad libitum. The body weight of the animals used for the experiment was $34.9 \pm 1.3 \mathrm{~g}$ (mean $\pm \mathrm{SD})$.

\section{Experimental procedure}

The experiment was conducted during daytime (PM 1:00-5:00). The experimental room was controlled as the same temperature and humidity as the animal room. The mice were weighed before receiving anesthesia.

In the first experiment, the anesthetic mixture was administered by IP, IV and SC injection at $0.1 \mathrm{ml} / 10 \mathrm{~g}$ b.w./mouse. We used 8 mice per each injection group and 9 mice for a group of non-anesthesia. The mice were used repeatedly and allowed at least 2 days of rest after experimental use. After the injection of anesthesia, the mouse was kept on a heater pad (Heater Mat KN- $475^{\circledR}$, Natsume Seisakusho, Co., Ltd., Tokyo, Japan) maintained at approximately $38^{\circ} \mathrm{C}$. After injection of the anesthetic mixture, an anesthetic score for each mouse was measured every 5 min until the mouse was completely recovered from anesthesia. At the same time, we measured $\mathrm{O}_{2}$-saturation, heart rate and respiratory rate using a pulse oximeter.

In the second experiment, we used 4 groups of mice. Drugs were administered using IP injection. Each group of 6 mice was given ATI after administration of the anesthetic mixture. Group $1: 0.3 \mathrm{mg} / \mathrm{kg}$ b.w. ATI at $30 \mathrm{~min}$ after administration of the anesthetic mixture. Group2: $1.5 \mathrm{mg} / \mathrm{kg}$ b.w. ATI at $30 \mathrm{~min}$ after administration of the anesthetic mixture. Group 3: $0.3 \mathrm{mg} / \mathrm{kg}$ b.w. ATI at 10 min after administration of the anesthetic mixture. Group 4: $1.5 \mathrm{mg} / \mathrm{kg} \mathrm{b}$.w. ATI at $10 \mathrm{~min}$ after administration of the anesthetic mixture. After administration of the anesthetic mixture, an anesthetic score was measured every 5 min. After injection of ATI, an anesthetic score was measured every $1 \mathrm{~min}$.

After finishing the experiment, the mice were euthanized by IV injection of sodium pentobarbital $(80 \mathrm{mg} /$ kg b.w.) (Somnopentyl ${ }^{\circledR}$, Kyoritsu Seiyaku Corporation, Tokyo, Japan). 


\section{Measuring anesthetic scores}

We briefly explain the method of measuring anesthetic scores that we previously described elsewhere [14]. Measurement was based on 5 reflexes. The first was a front paw reflex. The second was a hind paw reflex. The third was a tail reflex. The fourth was a corneal reflex. The fifth was a body-righting reflex. If a mouse showed no reflex, it was given a score of 1 . If a mouse reacted, it was given a score of 0 . The total anesthetic score was graded from 0 to 5 . The duration for which a mouse showed a score of 4 or 5 was decided to be the anesthetic duration.

Measurement of $\mathrm{O}_{2}$-saturation, heart rate and respiratory rate

A pulse oximeter (Mouse Ox plus ${ }^{\circledR}$, STARR Life Sciences Corp., Oakmont, PA, UAS) was used to measure $\mathrm{O}_{2}$-saturation, heart rate and respiratory rate of mice during the experiment. The day before the experiment, all hair covering both carotid arteries of the mice was removed using an electric shaver and a depilatory under inhalational isoflurane anesthesia (Escain ${ }^{\circledR}$, Mylan Seiyaku, Tokyo, Japan) using an anesthetic instrument (KN1071-I, Natsume Seisakusho, Co., Ltd., Tokyo, Japan).

A sensor clip of the pulse oximeter was placed at the cervical parts of the mice. Then, we recorded $\mathrm{O}_{2}$-saturation, heart rate and respiratory rate until each mouse was recovered from anesthesia. Measurement of mice without anesthesia was carried out in a mouse holder.

\section{Drug preparation}

The anesthetic mixture was prepared as a mix of three drugs: MED (Domitor ${ }^{\circledR}$, Nippon Zenyaku Kogyo Co., Ltd., Tokyo, Japan), MID (Dormicum ${ }^{\circledR}$, Astellas Pharma Inc., Tokyo, Japan) and BUT (Vetorphale ${ }^{\circledR}$, Meiji Seika Pharma Co., Ltd., Tokyo, Japan). We mixed MED 0.3 $\mathrm{mg}$, MID $4 \mathrm{mg}$ and BUT $5 \mathrm{mg} / \mathrm{kg}$ b.w./ mouse and added distilled sterile water (Otsuka sterile water ${ }^{\circledR}$, Otsuka Pharmaceutical Factory, Inc., Tokushima, Japan) to adjust it to an administrative volume of $0.1 \mathrm{ml} / 10 \mathrm{~g}$ b.w./mouse. For example, $0.3 \mathrm{ml}$ of Domitor, $0.8 \mathrm{ml}$ of Dormicum, $1.0 \mathrm{ml}$ of Vetorphale, and $7.9 \mathrm{ml}$ of distilled sterile water were mixed to make $10 \mathrm{ml}$ of an experimental anesthetic mixture. The anesthetic mixture was prepared on the day before the experiment and kept in a refrigerator. The mixed drug was allowed to be used up to 1 week after being mixed.

In the second experiment, we made $1.5 \mathrm{mg} / \mathrm{kg}$ b.w./ mouse of ATI (Antisedan ${ }^{\circledR}$, Nippon Zenyaku Kogyo Co., Ltd., Tokyo, Japan) to adjust it to an administrative volume of $0.1 \mathrm{ml} / 10 \mathrm{~g}$ b.w./mouse. To make $10 \mathrm{ml}$ of 1.5 $\mathrm{mg} / \mathrm{kg}$ of ATI, $0.3 \mathrm{ml}$ of Antisedan and $9.7 \mathrm{ml}$ of distilled sterile water were mixed. To make $0.3 \mathrm{mg} / \mathrm{kg}$ of ATI, 1 $\mathrm{ml}$ of a solution of $1.5 \mathrm{mg} / \mathrm{kg}$ of ATI and $4.0 \mathrm{ml}$ of distilled sterile water were mixed. The solution of ATI was also allowed to be used up to 1 week after being made.

Drug preparation was conducted at a clean bench in a sterile manner. Before administration, the drug was kept in the incubator of which temperature is around $37^{\circ} \mathrm{C}$.

\section{Statistical analysis}

Statistical analysis was conducted using Stat View software (Hulinks Inc., Tokyo, Japan). Data of graphs were presented as means \pm SD until 90 min after drug administration. Differences between each experimental groups were analyzed by analysis of variance (ANOVA) followed by Scheffe's test. A $P$ value less than 0.05 was considered to be statistically significant.

\section{Results}

All mice used in this experiment were recovered from anesthesia.

\section{First experiment}

\section{Body weight}

There were no significant differences of body weights of the 4 groups in the male ICR mice (Table 1).

\section{Anesthetic duration}

The anesthetic durations of IP, SC and IV injection groups were $45.6 \pm 7.8,56.9 \pm 14.1$ and $44.4 \pm 12.7 \mathrm{~min}$, respectively (Fig. 1). There were no significant differences among the three groups. The shortest anesthetic durations of IP, SC and IV injection groups were 35, 35 and $25 \mathrm{~min}$, respectively. The longest anesthetic durations of IP, SC and IV injection were 55, 80 and $70 \mathrm{~min}$, respectively (Table 1). The recovery times (at time when mice return from body-righting reflex) of IP, SC and IV injection groups were $68.8 \pm 7.9,76.3 \pm 16.2$ and 62.5 $\pm 16.3 \mathrm{~min}$, respectively (Fig. 2). The shortest recovery times of IP, SC and IV injection were 55, 55 and $50 \mathrm{~min}$, respectively. The longest recovery times of IP, SC and IV injection groups were 80, 105 and $100 \mathrm{~min}$, respectively. (Table 1). 
Table 1. Body weight (g), anesthetic duration ( $\mathrm{min}$ ) and recovery time of intraperitoneal (IP), subcutaneous (SC), intravenous (IV) and non-anesthesia groups of male ICR mice

\begin{tabular}{|c|c|c|c|c|c|c|c|c|}
\hline \multirow{2}{*}{ Route } & \multirow{2}{*}{ n. } & \multirow{2}{*}{$\frac{\text { Body weight }(\mathrm{g})}{\text { Mean } \pm \mathrm{SD}}$} & \multicolumn{3}{|c|}{ Anesthetic duration (min) } & \multicolumn{3}{|c|}{ Recovery time (min) } \\
\hline & & & Mean \pm SD & Shortest & Longest & Mean \pm SD & Shortest & Longest \\
\hline IP & 8 & $34.7 \pm 0.9$ & $45.6 \pm 7.8$ & 35 & 55 & $68.8 \pm 7.9$ & 55 & 80 \\
\hline $\mathrm{SC}$ & 8 & $34.9 \pm 0.5$ & $56.9 \pm 14.1$ & 35 & 80 & $76.3 \pm 16.2$ & 55 & 105 \\
\hline IV & 8 & $35.4 \pm 0.9$ & $44.4 \pm 12.7$ & 25 & 70 & $62.5 \pm 16.3$ & 50 & 100 \\
\hline Non & 9 & $34.8 \pm 1.4$ & - & - & - & - & - & - \\
\hline
\end{tabular}

Data are presented as means $\pm \mathrm{SD}$, as well as the shortest and longest time of injection groups. Differences between each experimental groups were analyzed by ANOVA followed by Scheffe's test. A $P$ value less than 0.05 was considered to be statistically significant. There were no significant differences of body weights among the 4 groups, as well as no significant differences of anesthetic durations and recovery time of 3 injection groups.

\section{Anesthetic Duration}

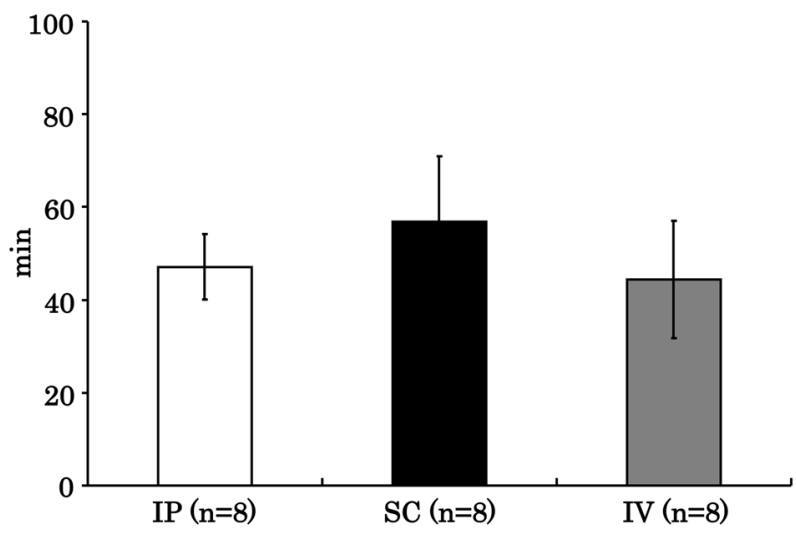

Fig. 1. Anesthetic duration of IP, SC and IV groups injected the anesthetic mixture in male ICR mice. Data are presented as means $\pm \mathrm{SD}$. Differences between each injection group were analyzed by ANOVA followed by Scheffe's test. A $P$ value less than 0.05 was considered to be statistically significant. There were no significant differences among the 3 groups.

\section{Anesthetic score}

The anesthetic scores of IP, SC and IV injection groups at 5 min after the administration of the anesthetic mixture were $2.8 \pm 0.7,3.4 \pm 0.7$ and $3.8 \pm 0.5$, respectively. The anesthetic score of IV injection group at 5 min was significantly higher than IP injection group. There were no significant differences of the anesthetic scores between $\mathrm{SC}$ and IV injection groups at $5 \mathrm{~min}$. There are no significant differences of the scores among the three groups at other time points (Fig. 3).

\section{Measurement by pulse oximeter}

1) $\mathrm{O}_{2}$-saturation

There were no significant differences of $\mathrm{O}_{2}$-saturation between the 3 groups before drug administration as well

\section{Recovery Time from Anesthesia}

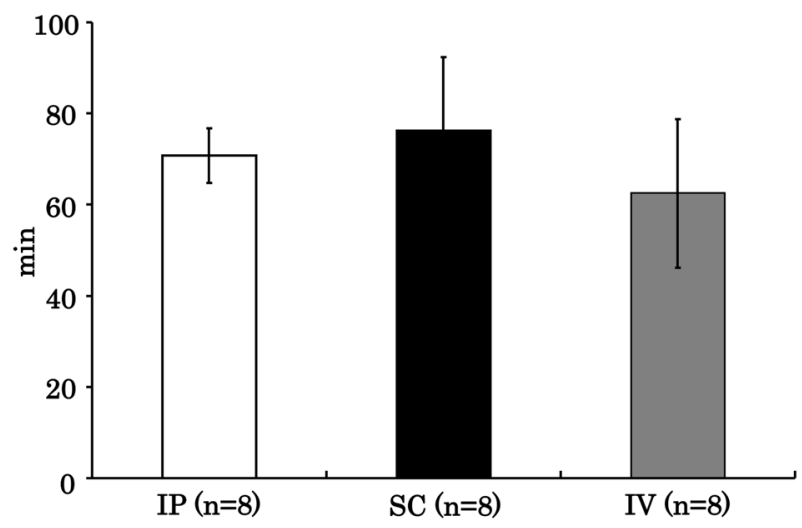

Fig. 2. Recovery time from anesthesia of IP, SC and IV groups injected the anesthetic mixture in male ICR mice. Data are presented as means $\pm \mathrm{SD}$. Differences between each injection group were analyzed by ANOVA followed by Scheffe's test. A $P$ value less than 0.05 was considered to be statistically significant. There were no significant differences among the 3 groups.

as the non-anesthesia group. The non-anesthesia group showed normal $\mathrm{O}_{2}$-saturation of $95.4 \pm 2.1 \%$ during 90 min. After the drug administration, $\mathrm{O}_{2}$-saturations of IP, $\mathrm{SC}$ and IV injection groups showed lower than that of the non-anesthesia group throughout the experiment (excluding at 70, 85 and $90 \mathrm{~min}$ ). $\mathrm{O}_{2}$-saturation levels of IP, SC and IV injection at $5 \mathrm{~min}$ after the administration were $83.2 \pm 2.7,78.2 \pm 7.6$ and $69.7 \pm 6.2 \%$, respectively. $\mathrm{O}_{2}$-saturation of $\mathrm{SC}$ and IV injection at $5 \mathrm{~min}$ was significantly lower than that of IP injection. $\mathrm{O}_{2}$-saturation levels of IV injection at 10, 25, 35, 40, 45, 70 and 75 min and SC injection from at 40 to 80 min were significantly lower than that of the IP injection (Fig. 4). 


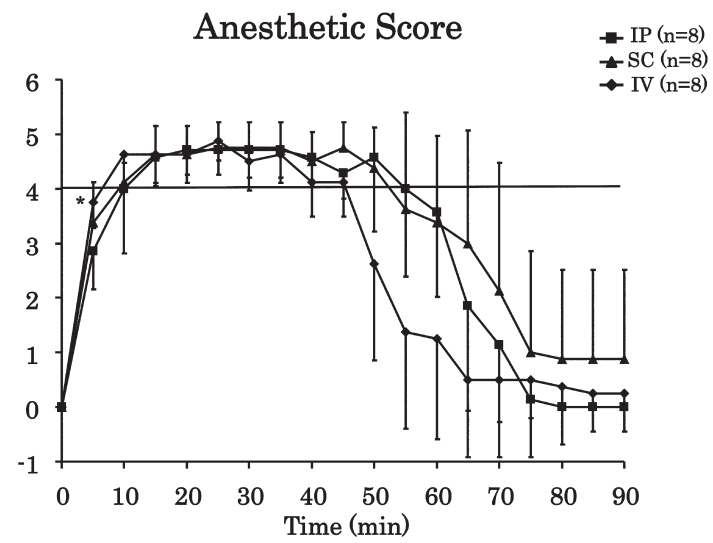

Fig. 3. Anesthetic score of IP, SC and IV groups injected the anesthetic mixture in male ICR mice. Data are presented as means \pm SD. Differences between each injection group were analyzed by ANOVA followed by Scheffe's test. A $P$ value less than 0.05 was considered to be statistically significant. $* P<0.05$ compared with the IP injection group.

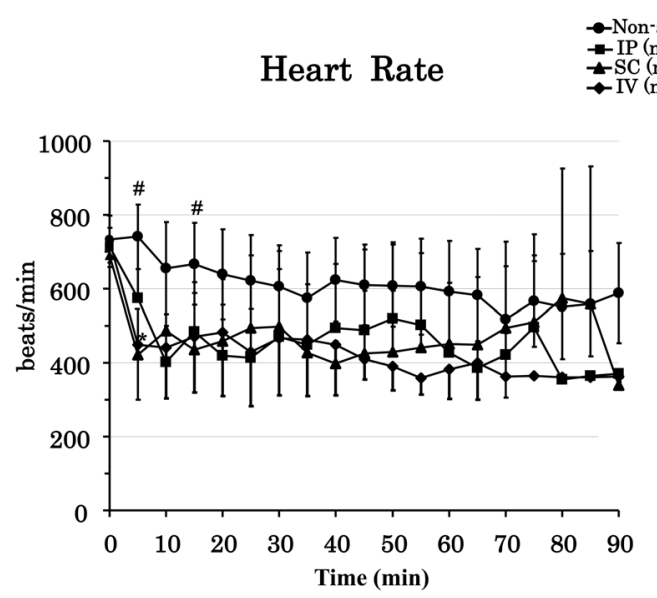

Fig. 5. Heart Rate of IP, SC and IV groups injected the anesthetic mixture, and the Non-anesthesia group in male ICR mice. Data are presented as means $\pm \mathrm{SD}$. Differences between each group were analyzed by ANOVA followed by Scheffe's test. A $P$ value less than 0.05 was considered to be statistically significant. ${ }^{*} P<0.05$ compared with the IP injection group. $\# P<0.05$ compared with the Non-anesthesia group.

\section{2) Heart rate}

There were no significant differences of heart rate between the 3 groups before drug administration as well as the non-anesthesia group. Heart rates of the non-anesthesia, IP, SC and IV injection groups at 5 min after the administration were $723 \pm 93,574 \pm 175,421 \pm 123$ and $449 \pm 148$ beats /min, respectively. Heart rates of three injection groups at 5 and 15 min were significant-

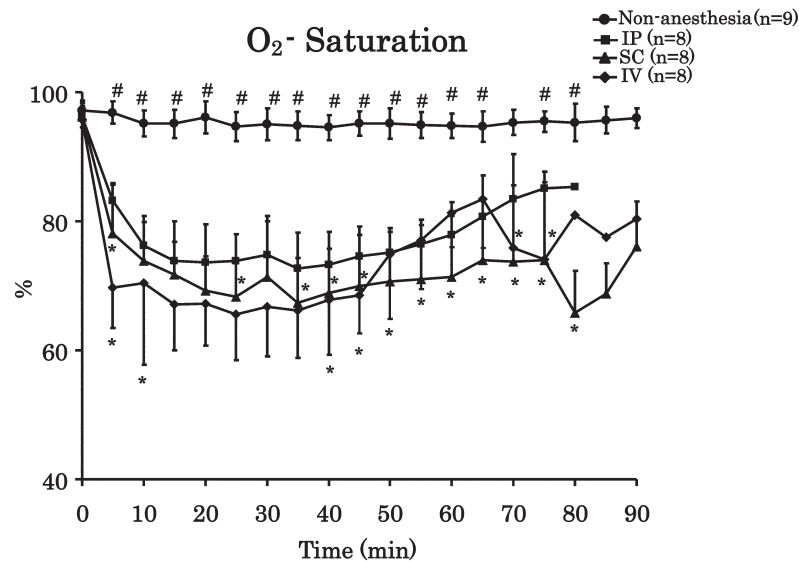

Fig. 4. $\mathrm{O}_{2}$-Saturation of IP, $\mathrm{SC}$ and IV groups injected the anesthetic mixture, and the Non-anesthesia group in male ICR mice. Data are presented as means \pm SD. Differences between each group were analyzed by ANOVA followed by Scheffe's test. A $P$ value less than 0.05 was considered to be statistically significant. $* P<0.05$ compared with the IP injection group. $\# P<0.05$ compared with the IP, SC and IV injection groups.

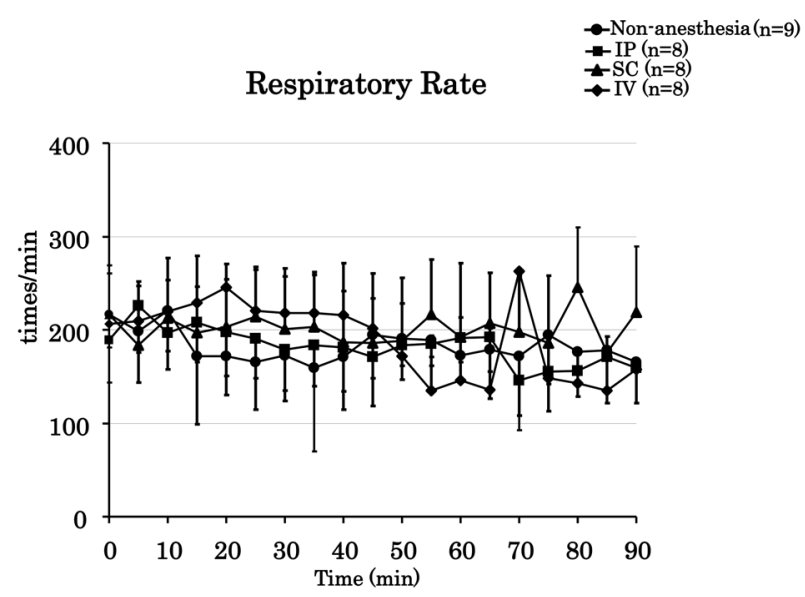

Fig. 6. Respiratory Rate of IP, SC and IV groups injected the anesthetic mixture, and the Non-anesthesia group in male ICR mice. Data are presented as means \pm SD. Differences between each group were analyzed by ANOVA followed by Scheffe's test. A $P$ value less than 0.05 was considered to be statistically significant. There were no significant differences among the 4 groups.

ly lower than the non-anesthesia group. Heart rates of IV injection groups at 5 min was significantly lower than the IP injection group (Fig. 5).

\section{3) Respiratory rate}

There were no significant differences of respiratory rates between the 3 groups before and after the drug administration as well as the non-anesthesia group (Fig. 6). 
Table 2. Second experiment procedure and body weight of mice

\begin{tabular}{|c|c|c|c|c|c|c|}
\hline \multirow{2}{*}{ Group } & \multirow{2}{*}{ n. } & \multirow{2}{*}{$\frac{\text { Body weight }(\mathrm{g})}{\text { Mean } \pm \mathrm{SD}}$} & \multirow{2}{*}{$\frac{\text { Mixed drug }}{\text { Route }}$} & \multicolumn{2}{|c|}{ Atipamezole } & \multirow{2}{*}{$\begin{array}{l}\text { Injection timing after } \\
\text { anesthetic mixture ( } \mathrm{min})\end{array}$} \\
\hline & & & & Route & Concentration & \\
\hline 1 & 6 & $34.3 \pm 2.2$ & IP & IP & $0.3 \mathrm{mg} / \mathrm{kg}$ & 30 \\
\hline 2 & 6 & $34.4 \pm 1.3$ & IP & IP & $1.5 \mathrm{mg} / \mathrm{kg}$ & 30 \\
\hline 3 & 6 & $34.6 \pm 1.4$ & IP & IP & $0.3 \mathrm{mg} / \mathrm{kg}$ & 10 \\
\hline 4 & 6 & $34.3 \pm 0.6$ & IP & IP & $1.5 \mathrm{mg} / \mathrm{kg}$ & 10 \\
\hline
\end{tabular}

Data of body weight are presented as means \pm SD. Differences between each experimental group were analyzed by ANOVA followed by Scheffe's test. A $P$ value less than 0.05 was considered to be statistically significant. There were no significant differences of body weights among the 4 groups.

A

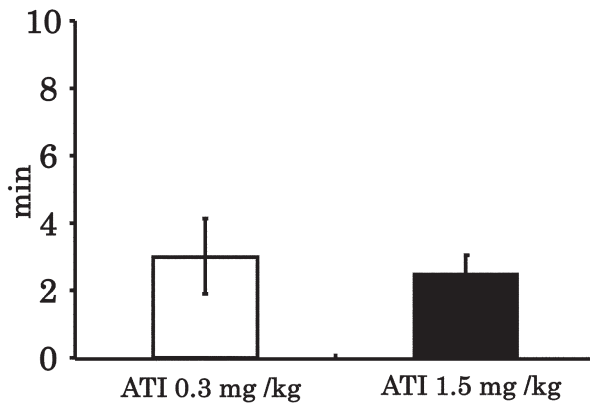

B

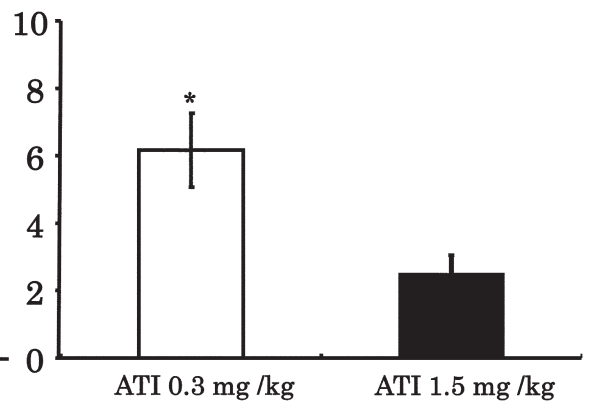

Fig. 7. Recovery time from anesthesia by IP injection of ATI $(0.3 \mathrm{mg} / \mathrm{kg}$ or $1.5 \mathrm{mg} / \mathrm{kg})$ at $30 \mathrm{~min}$ (A) and $10 \mathrm{~min}$ (B) after the administration of the anesthetic mixture in male ICR mice. Data are presented as means \pm SD. Differences between each group were analyzed by ANOVA followed by Scheffe's test. A $P$ value less than 0.05 was considered to be statistically significant. ${ }^{*} P<0.05$ compared with ATI $1.5 \mathrm{mg} / \mathrm{kg}$.

\section{Second experiment}

\section{Body weight}

There were no significant differences of body weights of the four groups in male ICR mice (Table 2).

\section{Recovery time from anesthesia}

At 30 min after injection of the anesthetic mixture, the recovery times of mice administered $0.3 \mathrm{mg} / \mathrm{kg}$ and $1.5 \mathrm{mg} / \mathrm{kg}$ of ATI were $3.0 \pm 1.1$ and $2.5 \pm 0.6 \mathrm{~min}$, respectively. There were no significant differences between the two dosages of ATI. At 10 min after injection of the anesthetic mixture, the recovery times of mice administered $0.3 \mathrm{mg} / \mathrm{kg}$ and $1.5 \mathrm{mg} / \mathrm{kg}$ of ATI were $6.2 \pm 2.0$ and $2.5 \pm 0.6 \mathrm{~min}$, respectively. The recovery time of $1.5 \mathrm{mg} /$ $\mathrm{kg}$ of ATI was significantly shorter than $0.3 \mathrm{mg} / \mathrm{kg}$ of ATI at 10 min after injection of the anesthetic mixture (Fig. 7).

\section{Anesthetic score}

There were no significant differences of anesthetic scores between two dosages of ATI at $30 \mathrm{~min}$ after the administration of the anesthetic mixture. At 10 min after injection of the anesthetic mixture, the anesthetic scores of ATI $(0.3 \mathrm{mg} / \mathrm{kg})$ was significantly higher than that of ATI $(1.5 \mathrm{mg} / \mathrm{kg}$ ) from 2 to $6 \mathrm{~min}$ after injection (Fig. 8).

\section{$\mathrm{O}_{2}$-saturation}

There were no significant differences of $\mathrm{O}_{2}$-saturation levels between two dosages of ATI when administered at $30 \mathrm{~min}$ after injection of the anesthetic mixture. At 10 min after injection of the anesthetic mixture, the $\mathrm{O}_{2}$ saturation level of ATI $(1.5 \mathrm{mg} / \mathrm{kg})$ was significantly higher than ATI $(0.3 \mathrm{mg} / \mathrm{kg})$ at 2 and 3 min after injection (Fig. 9).

\section{Discussion}

The anesthetic mixture of MED, MID and BUT for mice has been introduced recently [13]. Originally this mixture has been used as anesthesia for dogs $[11,16$, 18], monkeys [12, 15] and African lions in a zoo [19]. 


\section{Anesthetic Score}
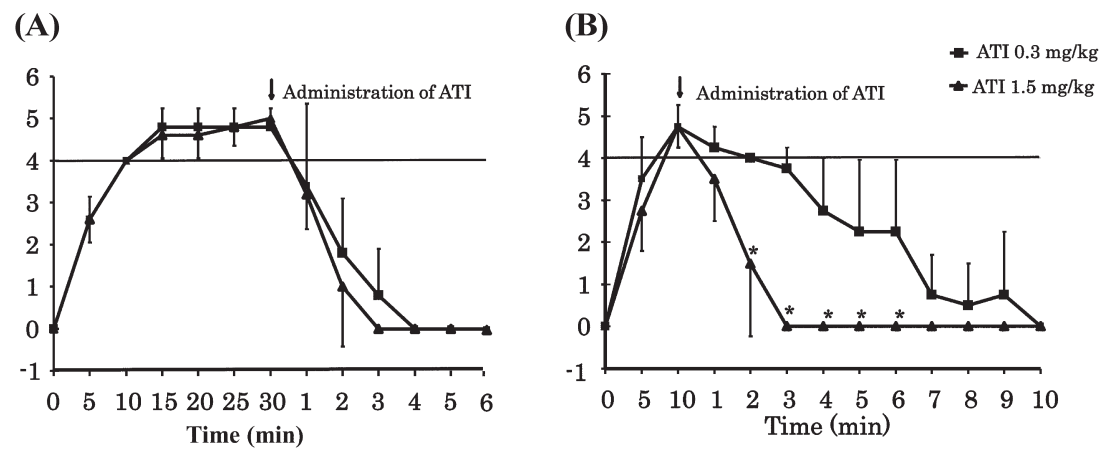

Fig. 8. Anesthetic score of male ICR mice injected ATI $(0.3 \mathrm{mg} / \mathrm{kg}$ or $1.5 \mathrm{mg} / \mathrm{kg}) 30 \mathrm{~min}$ (A) or $10 \mathrm{~min}$ (B) after the administration of the anesthetic mixture. Data are presented as means $\pm \mathrm{SD}$. Differences between each injection group were analyzed by ANOVA followed by Scheffe's test. A $P$ value less than 0.05 was considered to be statistically significant. $* P<0.05$ compared with the ATI $0.3 \mathrm{mg} / \mathrm{kg}$ injection group $10 \mathrm{~min}$ after the administration of the anesthetic mixture.

\section{$\mathrm{O}_{2}$ - Saturation}

\section{(A)}

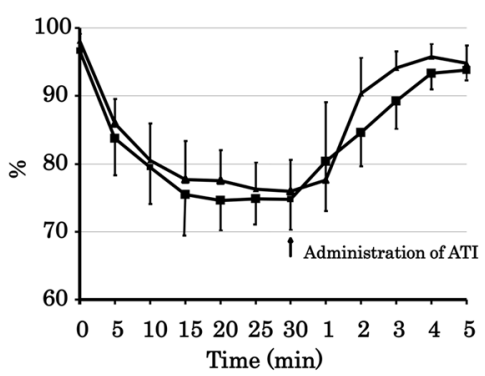

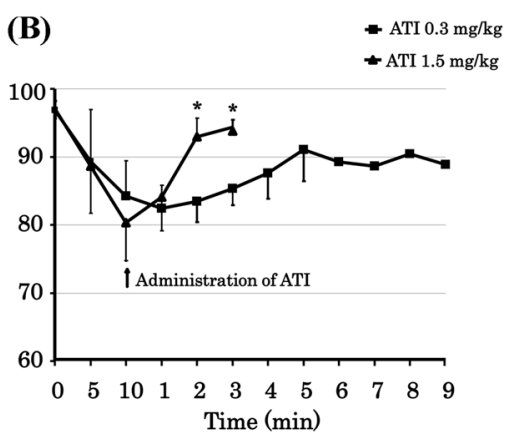

Fig. 9. $\mathrm{O}_{2}$-Saturation of male ICR mice injected ATI $(0.3 \mathrm{mg} / \mathrm{kg}$ or $1.5 \mathrm{mg} / \mathrm{kg})$ at $30 \mathrm{~min}$ (A) or $10 \mathrm{~min}(\mathrm{~B})$ after the administration of the anesthetic mixture. Data are presented as means \pm SD. Differences between each injection group were analyzed by ANOVA followed by Scheffe's test. A $P$ value less than 0.05 was considered to be statistically significant. $* P<0.05$ compared with the ATI $0.3 \mathrm{mg} / \mathrm{kg}$ injection group 10 min after the administration of the anesthetic mixture.

This anesthetic mixture was reported to produce anesthetic duration of around $40 \mathrm{~min}$ in ICR mice [13]. We reported that this anesthetic mixture produced almost the same anesthetic effects in both male and female BALB/c and C57BL/6J strains [14]. Both mice studies described above used IP injection to administer the anesthetic mixture. IP injection of drugs has been widely used in mice [10], because SC injection induces drug effects more slowly and weakly than IP injection [9]. IV injection produces drug effects more quickly and predictably [8]. However, rapid IV injection of anesthetic drugs is sometimes lethal. In this study, the first experiment indicated that there were no significant differences of anesthetic duration among the three different injection routes (Fig. 1), although the IV injection group showed a quick increase and decrease of anesthetic scores after injection (Fig. 3). The anesthetic score of the IV injection group was significantly higher than the IP injection group at $5 \mathrm{~min}$. From 10 to $90 \mathrm{~min}$, the three injection groups did not show statistically different anesthetic scores. However, our scoring method to estimate anesthetic depth could not measure an anesthetic score of over 5 . As the result of $\mathrm{O}_{2}$-saturation levels showed, IV injection may have worked more strongly than IP injection during the earlier period after injection.

Unexpectedly, SC injection showed a tendency to 
produce longer anesthetic duration compared to IP injection (Fig. 1). Claassen reported that IP injection technique has a failure rate of $10-20 \%$ [3]. An IP injection is made through the abdominal wall into the peritoneal cavity and there is no visual confirmation that the injection has been correctly administered [10]. Compared to IP injection, inspectional failures are easily detected with SC and IV injection routes. In our study, all SC and IV injections were conducted successfully with visual confirmation. Burnside et al. reported that there were no significant differences of anesthetic durations between IP and SC injection for a mixed drug of KET and MED in mice [2]. Their study said that SC injection may be considered preferable to prevent additional stress to animals, as well as potential damage to internal organs that may occur by IP injection. Then, we recommend SC injection of the anesthetic mixture compared to IP and IV injection, although there are no significant differences of anesthetic duration among the three injection routes.

It is very difficult to explain the precise mechanism as to why there were no significant differences of anesthetic duration among the three different injection routes. The three drugs each have a different pharmacological mechanism. MED is an alpha ${ }_{2}$-adrenargic agonist to produce sedative and analgesic effects [4]. MID is a benzodiazepine receptor agonist to produce sedation [4]. BUT acts at opioid $\kappa$-receptors to produce analgesic effects, but it is an opioid $\mu$-receptor antagonist [5]. Salonen et al. reported that there was synergistic interaction between dexmedetomidine (alpha ${ }_{2}$-adrenargic agonist) and MID in rats [17]. In our study, MED may work synergistically to improve effects when mixed with MID and BUT. The result of the second experiment showed that the injection of ATI $(1.5 \mathrm{mg} / \mathrm{kg})$ caused mice to have perfect recovery from anesthesia within 10 min after administration of the anesthetic mixture. At this time point, usually pharmacological effects of MID and BUT still remain after a single administration.

$\mathrm{O}_{2}$-saturations of the three injection groups showed a lower $\mathrm{O}_{2}$-saturation level compared to the non-anesthesia group during the experiment. $\mathrm{O}_{2}$-saturations of IV injection at 5 and 10 min were significantly lower than IP injection (Fig. 4) and recovered after 50 min just like reducing anesthetic scores (Fig. 3). Heart rates of anesthesia injection groups were significantly decreased at 5 or $15 \mathrm{~min}$ after injection compared to the non-anesthesia group. However, during the anesthesia after $20 \mathrm{~min}$ of administration of the anesthetic mixture, heart rates of each anesthetic injection group showed a stable condition (Fig. 5). Respiratory rate did not affect the difference of any injection route or the non-anesthesia condition. Therefore, $\mathrm{O}_{2}$-saturation is a suitable parameter to estimate anesthetic depth and condition under anesthesia for laboratory animals.

ATI is an alpha $a_{2}$-adrenargic antagonist, then it antagonizes the effect of MED [7]. At 30 min after the anesthetic mixture, administration of ATI at $0.3 \mathrm{mg} / \mathrm{kg}$ and $1.5 \mathrm{mg} / \mathrm{kg}$ had almost the same rapid recovery time from anesthesia (Fig. 7). However, at 10 min after injection of the anesthetic mixture, administration of ATI at $0.3 \mathrm{mg} / \mathrm{kg}$ needed more time to recover from anesthesia compared to ATI (1.5 mg/kg) (Fig. 7). Baker et al. reported that there were no significant differences of recovery times after receiving $5 \mathrm{mg} / \mathrm{kg}$ of ATI at $10 \mathrm{~min}$ and $40 \mathrm{~min}$ after administration of a combination of KET $(75 \mathrm{mg} / \mathrm{kg})$ and MED $(1 \mathrm{mg} / \mathrm{kg})$ [1]. Our data also showed no significant differences of recovery times at $10 \mathrm{~min}$ and $30 \mathrm{~min}$ after administration of the anesthetic mixture when administered ATI at $1.5 \mathrm{mg} / \mathrm{kg}$ (Fig. 7). In the study of Baker et al., a 5 times higher dosage of ATI $(5 \mathrm{mg} /$ $\mathrm{kg})$ than MED $(1 \mathrm{mg} / \mathrm{kg})$ was used. We also used a 5 times higher dosage of ATI $(1.5 \mathrm{mg} / \mathrm{kg})$ than MED $(0.3$ $\mathrm{mg} / \mathrm{kg}$ ). When mice are administered an anesthetic mixture to have surgery for around $30 \mathrm{~min}$, ATI at $0.3 \mathrm{mg}$ / $\mathrm{kg}$ is a large enough dosage to recover from anesthesia. ATI at $1.5 \mathrm{mg} / \mathrm{kg}$ is suitable to allow mice to recover from anesthesia quickly. $\mathrm{O}_{2}$-saturation levels after administration of ATI $1.5 \mathrm{mg} / \mathrm{kg}$ also indicated a quick recovery from anesthesia (Fig. 9).

In summary, our study indicated that an anesthetic mixture of MED, MID and BUT produced almost same anesthetic duration by IP, SC and IV injection in ICR mice. SC injection of the anesthetic mixture is a recommended route compared to IP or IV injection, because there are $10-20 \%$ of failure in IP injection, and IV method is not easy for injection. This anesthetic mixture is a useful drug to have a MED antagonist; ATI which helps mice quickly recover from anesthesia. These results may contribute to the welfare of laboratory animals.

\section{Acknowledgment}

The authors wish to thank Mr. John Telloyan of Shimane University, School of Medicine, for English assistance. 


\section{References}

1. Baker, N.J., Schofield, J.C., Caswell, M.D., and McLellan, A.D. 2011. Effects of early atipamezole reversal of medetomidine-ketamine anesthesia in mice. J. Am. Assoc. Lab. Anim. Sci. 50: 916-920. [Medline]

2. Burnside, W.M., Flecknell, P.A., Cameron, A.I., and Thomas, A.A. 2013. A comparison of medetomidine and its active enantiomer dexmedetomidine when administered with ketamine in mice. BMC Vet Res. 9: 48. doi: 10. 1186/17466148-9-78.

3. Claassen, V.1994. Neglected factors in pharmacology and neuroscience reserch. p. 46-58. In: Tecniques in the Behavioral and Neural Sciences. vol.12, ELSEVIER, Amsterdam.

4. Flecknell, P.A.2009. Chapter 2, Anesthesia. p.23. In: Laboratory Animal Anaesthesia, 3rd ed. ELSEVIER, London.

5. Flecknell, P.A.2009. Chapter 5, Analgesia and post-operative care. p.170. In: Laboratory Animal Anaesthesia, 3rd ed. ELSEVIER, London.

6. Flecknell, P.A.2009. Chapter 3, Analgesic management. p.83-87. In: Laboratory Animal Anaesthesia, 3rd ed. ELSEVIER, London.

7. Flecknell, P.A.2009. Chapter 2, Anesthesia. p.24. In: Laboratory Animal Anaesthesia, 3rd ed. ELSEVIER, London.

8. Flecknell, P.A.2009. Chapter 2, Anesthesia. p.63. In: Laboratory Animal Anaesthesia, 3rd ed. ELSEVIER, London.

9. Fujiwara, M., Kuriyama, K., and Hattori, K.1986. p.29-30. In: The Textbook of Medical Pharmacology. (Japanese) NANZANDO Co., Ltd., Tokyo.

10. Gaines, D.R. and North, D. 2007. Implications of experimental technique for analysis and interpretation of data from animal experiments: outliers and increased variability resulting from failure of intraperitoneal injection procedures. Lab. Anim. 41: 312-320. [Medline] [CrossRef]

11. Itamoto, K., Hikasa, Y., Sakonjyu, I., Itoh, H., Kakuta, T., and Takase, K. 2000. Anaesthetic and cardiopulmonary effects of balanced anaesthesia with medetomidine-midazolam and butorphanol in dogs. J. Vet. Med. A Physiol. Pathol. Clin Med. 47: 411-420. [Medline] [CrossRef]

12. Kalema-Zikusoka, G., Horne, W.A., Levine, J., and Loomis, M.R. 2003. Comparison of the cardiorespiratory effects of medetomidine-butorphanol-ketamine and medetomidinebutorphanol-midazolam in patas monkeys (Erythrocebus patas). J. Zoo Wildl. Med. 34: 47-52. [Medline]

13. Kawai, S., Takagi, Y., Kaneko, S., and Kurosawa, T. 2011. Effect of three types of mixed anesthetic agents alternate to ketamine in mice. Exp. Anim. 60: 481-487. [Medline] [CrossRef]

14. Kirihara, Y., Takechi, M., Kurosaki, K., Kobayashi, Y., and Kurosawa, T. 2013. Anesthetic effects of a mixture of medetomidine, midazolam and butorphanol in two strains of mice. Exp. Anim. 62: 173-180. [Medline] [CrossRef]

15. Ochi, T., Nishiura, I., Tatsumi, M., Hirano, Y., Yahagi, K., Sakurai, Y., Matsuyama-Fujiwara, K., Sudo, Y., Nishina, N., and Koyama, H. 2014. Anesthetic effect of a combination of medetomidine-midazolam-butorphanol in cynomolgus monkeys (Macaca fascicularis). J. Vet. Med. Sci. 76: 917-921. [Medline] [CrossRef]

16. Pypendop, B. and Verstegen, J. 1999. Cardiorespiratory effects of a combination of medetomidine, midazolam, and butorphanol in dogs. Am. J. Vet. Res. 60: 1148-1154. [Medline]

17. Salonen, M., Reid, K., and Maze, M. 1992. Synergistic interaction between alpha 2-adrenergic agonists and benzodiazepines in rats. Anesthesiology 76: 1004-1011. [Medline] [CrossRef]

18. Verstegen, J. and Petcho, A. 1993. Medetomidine-butorphanol-midazolam for anaesthesia in dogs and its reversal by atipamezole. Vet. Rec. 132: 353-357. [Medline] [CrossRef]

19. Wenger, S., Buss, P., Joubert, J., Steenkamp, J., Shikwambana, P., and Hatt, J.M. 2010. Evaluation of butorphanol, medetomidine and midazolam as a reversible narcotic combination in free-ranging African lions (Panthera leo). Vet. Anaesth. Analg. 37: 491-500. [Medline] [CrossRef] 